\title{
OJS OPEN

\section{A LEITURA DE MUNDO A PARTIR DOS MAPAS TEMÁTICOS: ANÁLISE COMPARATIVA DOS MATERIAIS DIDÁTICOS DO BRASIL E DA ESPANHA}

\author{
Raiane Florentino $^{1}$ \\ 1E-mail: raianeflorentino@gmail.com \\ Artigo recebido em 02/04/2020 e aceito em 20/04/2020
}

\begin{abstract}
RESUMO
Ao conceber a Cartografia como uma ferramenta que possibilita explicar, interpretar e representar o espaço, acredita-se que a mesma permite efetuar o raciocínio geográfico através dos mapas temáticos, que possuem o objetivo de aprofundar os estudos sobre os fenômenos espaciais e a dimensão destes, investigando, assim, a natureza, a dinâmica e a concepção destes fenômenos espaciais. No Brasil, os mapas temáticos são comumente utilizados como um método de ilustração e localização de locais. Na Espanha, observa-se que o mesmo ocorre, pois, muitas vezes seus materiais didáticos também se preocupam em demonstrar a localização de países e da ocorrência de fenômenos. Aliado ao fato de que o primeiro documento curricular padronizado escolar para o território brasileiro foi inspirado pelas reformas escolares espanholas, almeja-se exibir uma comparação entre os mapas inseridos nas propostas didáticas espanholas e brasileiras, apresentando os resultados obtidos a partir dos materiais didáticos utilizados pelas escolas públicas do estado de São Paulo, na região sudeste do Brasil, denominado de Caderno do Professor e do livro didático Geografia e História, da Espanha. Este estudo utilizou um esquema desenvolvido com base no pensamento espacial para explorar a complexidade dos exercícios que envolvem mapas temáticos.
\end{abstract}

Palavras-chave: Material didático; Pensamento Espacial; Cartografia; Brasil; Espanha.

\section{WORLD READING FROM THEMATIC MAPS: COMPARATIVE ANALYSIS OF TEACHING MATERIALS IN BRAZIL AND SPAIN}

\begin{abstract}
When designing Cartography as a tool that makes it possible to explain, interpret and represent space, it is believed that it allows geographic reasoning to be carried out through thematic maps, which aim to deepen the studies on spatial phenomena and their dimension, thus investigating the nature, dynamics and conception of these spatial phenomena. In Brazil, thematic maps are commonly used as a method of illustration and location of places. In Spain, it is observed that the same occurs, because, often, their teaching materials are also concerned with demonstrating the location of countries and the occurrence of phenomena. Allied to the fact that the first standardized school curriculum document for the Brazilian territory was inspired by the Spanish school reforms, it aims to show a comparison between the maps inserted in the Spanish and Brazilian didactic proposals, presenting the results obtained from the didactic materials used by public schools in the state of São Paulo, in the southeastern region of Brazil, called the Teacher's Notebook and the textbook Geography i Història, from Spain. This study used a scheme developed based on spatial thinking to explore the complexity of exercises that involve thematic maps.
\end{abstract}

Keywords: Courseware, Spatial Thinking, Cartography, Brazil, Spain. 


\section{INTRODUÇÃO}

Os mapas temáticos possibilitam representar, explicar e interpretar fenômenos, além de representar o espaço geográfico, pois se designam a responder questões como: Onde? Quando? Por quê? Tornando possível identificar a natureza, a dinâmica e a concepção dos fenômenos de forma ampla ou isolada, dependendo da escala utilizada, possibilitando assim uma gama de informações. Apesar disso, os mapas comumente são utilizados para informar e ilustrar a localização de lugares ou elementos, principalmente quando se trata de questões inseridas em materiais didáticos. Isto se comprova quando se realiza uma pesquisa de cunho qualitativo como esta, que compara materiais didáticos de dois países diferentes, e observa-se que o mesmo ocorre em ambos.

No Brasil, grande parte dos materiais didáticos ainda aborda os mapas temáticos para ilustrar a ocorrência de determinada situação que influencia na geografia da área representada. A partir da leitura dos artigos de Tonini et. al. (2017), observa-se que este hábito comparece também nos livros didáticos distribuídos nas escolas espanholas e portuguesas. Nestes casos, os mapas estão acompanhados de exercícios que possuem a preocupação de demonstrar, por exemplo, onde ocorrem as questões regionais sobre clima e relevo, deixando de lado a análise e a interpretação dos fatores que influenciaram os mesmos. Sem isso, a criticidade e o olhar reflexivo do estudante não é estimulada, e consequentemente não contribui para que ele compreenda os mecanismos de funcionamento de uma sociedade, os fatores climáticos, sociais, econômicos e políticos, além de impossibilitar e dificultar o desenvolvimento das habilidades espaciais, que são importantes para desenvolver as noções de localização, orientação, profundidade e distância, que estão relacionadas às operações cognitivas espaciais.

Nesse sentido, encontrou-se na literatura sobre o pensamento espacial elementos que favorecem este estimulo, pois através do pensamento espacial o indivíduo desenvolve habilidades que possibilita que ele se locomova em espaços tumultuados sem esbarrar em objetos ou outras pessoas, por exemplo. Baseado nessas aquisições positivas para o aumento das habilidades cognitivas, reflexivas, críticas e espaciais, despertou-se o interesse em realizar estudos que envolvam o pensamento espacial.

Portanto, os materiais didáticos foram analisados mensurando se os exercícios com mapas temáticos mobilizam o pensamento espacial. Para isso, utilizou-se como referência a taxonomia de Jo \& Bednarz (2009) e os estudos de Gersmehl \& Gersmehl (2007) e Simielli 
(1996). As bibliografias fornecem meios para explorar a complexidade dos exercícios que envolvem mapas temáticos e o raciocínio geográfico. Como objetos de análise, selecionamos o Caderno do Professor da $1^{\mathrm{a}}$ série do ensino médio como o material didático brasileiro e para o território espanhol, utilizamos o livro didático Geografia i Història, indicado para o 2 ESO, da Editora Santillana Educación (2007).

Com esta pesquisa concluímos que tanto o material brasileiro quanto espanhol apresentaram questões que envolvem habilidades espaciais, como também não espaciais. Algumas questões colaboram para aquisições cognitivas simples e outras mais complexas.

\section{EDUCAÇÃO BÁSICA NO BRASIL E NA ESPANHA}

A Educação Básica equivale ao período inicial de escolaridade de um indivíduo. Em alguns países ela incluí a educação infantil, outros não. Ela é obrigatória na maior parte dos países, mas há diferenças em relação ao conteúdo que é ensinado e também na questão sobre a faixa etária relativa às séries escolares.

$\mathrm{Na}$ Espanha, a Educação Básica tem duração de 10 anos, tendo início aos 6 e finalizando aos 15 anos. É gratuita e também obrigatória. Se divide da seguinte maneira: Educação Primária (dos 6 aos 11 anos), seguida da Educação Secundária Obrigatória (12 aos 15 anos). Diferente do que há no Brasil, na Espanha existe a Educação Secundária PósObrigatória, que contém o Bachillerato e a Formação Profissional de Grau Médio (FP). No Bachillerato os estudantes se preparam para o próximo degrau, que é o do Ensino Superior. Apenas quem concluir o Bachillerato poderá cursar o Ensino Superior. Já a Formação Profissional fornece uma educação voltada para o mercado de trabalho, e tem como prérequisito que o aluno tenha concluído a Educação Secundária Obrigatória.

O ensino básico brasileiro é gratuito e obrigatório, abrangendo estudantes dos 6 aos 17 anos de idade. O Ensino Fundamental é a primeira etapa, que vai dos 6 aos 14 anos, se dividindo em dois ciclos, o primeiro dos 6 aos 10 anos, e o segundo, dos 11 aos 14 anos. Depois vem o Ensino Médio, dos 15 aos 17 anos. O Ensino Superior não é obrigatório.

É importante esclarecer que desde os anos 90 observa-se o forte impulsionamento das políticas neoliberais e seus desdobramentos na educação brasileira, estimulando o "comércio do saber", ampliando a terceirização dos materiais didáticos e expandindo a produção didática. 
Além disso, nesse período foi estabelecido o primeiro documento curricular escolar para todo o território brasileiro, inspirado nas reformas escolares espanholas. Fruto dessa padronização curricular, em 2008, o estado de São Paulo introduziu seu próprio currículo através do programa São Paulo Faz Escola. A proposta incluía o Caderno do Professor que contem situações de aprendizagem com exercícios e instruções de como o professor deve abordar os temas do currículo escolar paulista.

\section{O PENSAMENTO ESPACIAL}

O pensamento espacial vem sendo difundido mundialmente desde 2006 pelo National Research Council (NRC), com a publicação intitulada Aprendendo a pensar espacialmente ${ }^{1}$ (NRC, 2006). Devido a sua capacidade interdisciplinar, podendo ser aplicado a Matemática e também a Geografia, tornou-se reconhecido, adotado e utilizado por muitos pesquisadores que tem o intuito de explorar e enriquecer as práticas pedagógicas. Para a Geografia, o pensamento espacial pode contribuir no processo de ensino-aprendizagem dos conceitos geográficos e na formação crítica do indivíduo, no sentido de conceder formas de compreender as dinâmicas que ocorrem no espaço geográfico.

Segundo consta no documento da NRC (2006, p. 36), o pensamento espacial é composto por três elementos centrais: representações, conceitos e processos de raciocínio. Acredita-se que também envolve conceitos relacionados ao espaço que permitem que o indivíduo desenvolva noções relacionadas à localização, distância, profundidade, orientação, além de possibilitar a representação do espaço geográfico em mapas temáticos, desenvolvendo e aprimorando habilidades cognitivas espaciais, que, segundo Gersmehl \& Gersmehl (2007), são elencadas em oito operações: comparação, proximidade, região, sequência, hierarquia, analogia, padrão e associação.

Além dessas operações, o pensamento espacial também deve estabelecer meios de responder questões que façam o indivíduo sintetizar, analisar e estabelecer a relação entre os fenômenos. Nesse aspecto, em seu estudo, Jo \& Bednarz (2009) realizaram a avaliação de exercícios didáticos segundo uma taxonomia, desenvolvida com o objetivo de investigar se a atividade apresenta elementos que mobilizem o pensamento espacial. Para tanto, a primeira análise consiste em observar se o exercício contem alguma representação espacial. Caso

\footnotetext{
$1 \quad$ Learning to think spatially.
} 
positivo, ele mobiliza o pensamento espacial e a taxonomia fornece vinte e quatro células para verificar a complexidade das habilidades espaciais que são exigidas para a sua resolução.

Essa taxonomia se divide em três níveis: entrada de pensamento (input), que envolve conceitos cognitivos para a coleta de dados e informações da representação espacial que esteja relacionada à identificação, reconhecimento, definição e recordação, não levando em conta o raciocínio. É o nível mais simples de todos. Depois, tem-se o nível de processamento de pensamento (processing), que exige a classificação, comparação e explicação das informações adquiridas no nível anterior. Este nível exige raciocínio, pois é necessário que se analise as informações coletadas. Por fim, o último nível é o de saída de pensamento (output), que está relacionado à geração de novos conhecimentos extraídos dos dois primeiros níveis. Ele também requer raciocínio e é o nível que exige mais complexidade.

O pensamento espacial envolve ainda o desenvolvimento de habilidades espaciais, tais como a visualização espacial, que representa a capacidade de se manipular, girar ou inverter os estímulos visuais tri ou bidimensionais, a orientação espacial, que permite visualizar uma figura numa perspectiva diferente, e as relações espaciais, a partir das observações feitas por De Miguel (2016). Inclui também a espacialidade do conceito, que pode ser não espacial, espacial primitivo, espacial simples ou espacial complexo, além de envolver o uso de ferramentas de representação, como o mapa temático. Ademais, o processo cognitivo mobiliza aquisições simples, médias e complexas, segundo Simielli (1999).

Desse modo, unindo todos estes elementos que concentram o pensamento espacial e as habilidades cognitivas desenvolvidas e estimuladas através do mesmo forma-se um esquema robusto para analisar as atividades didáticas que envolvem mapas temáticos. Essa união foi sistematizada no esquema a seguir, na Tabela 1.

Tabela 1. Análise do pensamento espacial

\begin{tabular}{|l|l|l|l|l|l|}
\hline Localização & Representação & Conceitos & $\begin{array}{c}\text { Nivel de } \\
\text { processamento }\end{array}$ & Habilidades & Aquisições \\
\hline & & & & & \\
\hline
\end{tabular}

Fonte: Elaboração própria. 
Os materiais didáticos selecionados foram avaliados a partir deste esquema, visando verificar se os exercícios com mapas temáticos estimulam e mobilizam o pensamento espacial dos estudantes.

\section{ANÁLISE DOS MATERIAIS}

Para realizar a análise do material didático, foi selecionado um exemplar de cada país, de uma série escolar aleatória. No caso do Brasil, o Caderno do Professor foi o escolhido. Este Caderno foi utilizado pelas escolas públicas paulistas nos últimos dez anos, sendo o material didático oficial desse estado. Ele utiliza como base curricular os Parâmetros Curriculares Nacionais (PCN), implantado no Brasil em 1998, como mencionado anteriormente.

Para a análise, selecionou-se o exemplar da $1^{\mathrm{a}}$ série do ensino médio. Na figura 1 , encontra-se o mapa identificado na página 85 do Caderno do Professor. Junto dele, haviam dez questões, sendo que 7 mobilizam o pensamento espacial, solicitando que o aluno identifique, compare e localize fenômenos no mapa. As demais perguntas são mais descritivas, cobrando que o escolar descreva o que é desflorestamento e desertificação, que constituem o tema do mapa.

Figura 1. Mapa temático sobre o desfloramento e a desertificação mundial, em 2016.

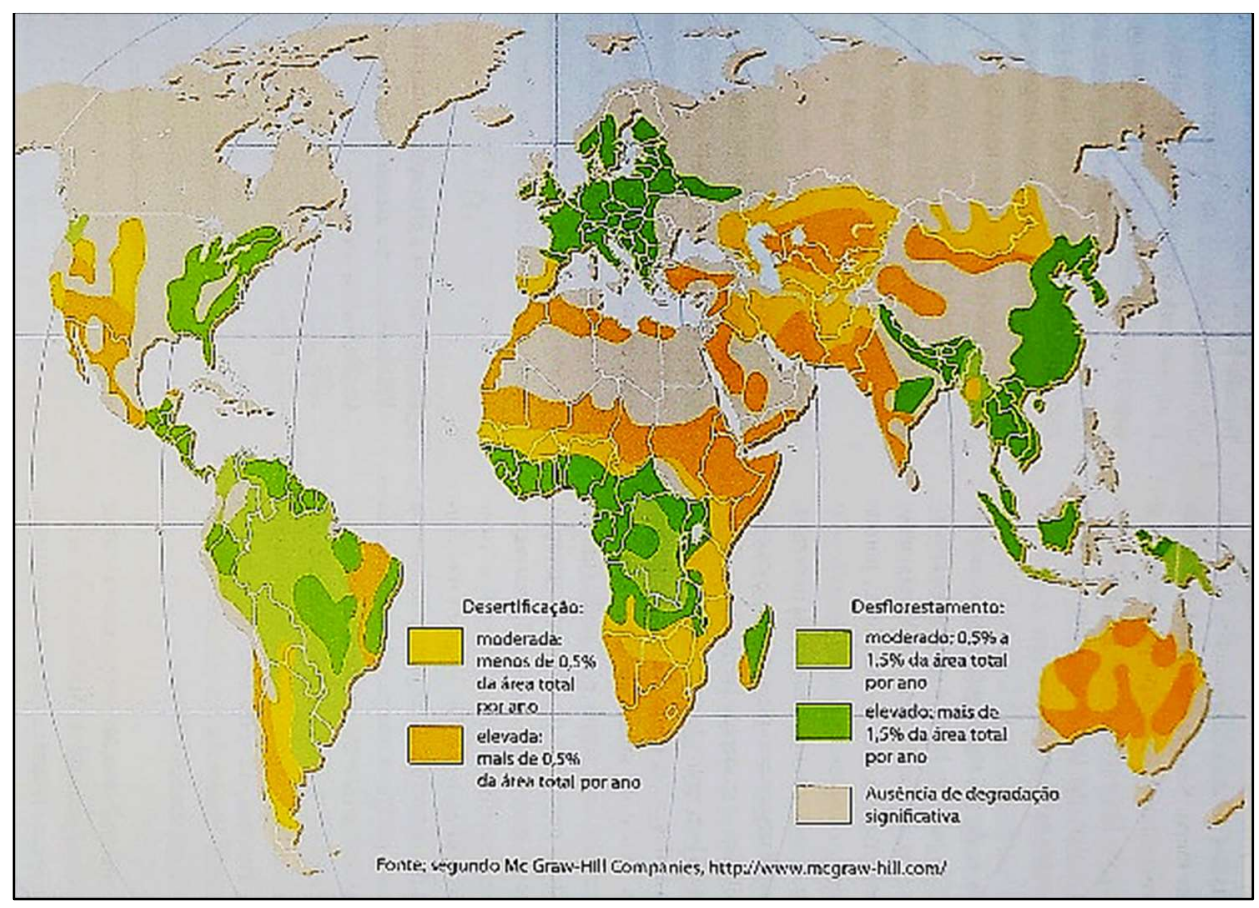

Fonte: SÃO PAULO, 2014. 
Na página 94 encontra-se o mapa da Figura 2 que representa o consumo per capita da energia primaria no mundo em 2012. Ele é abordado em duas questões e ambas mobilizam o pensamento espacial, pois o estudante deverá observar o mapa e explicar o motivo de algumas regiões ilustradas no mapa consumirem mais energia do que as outras, além de solicitar que ele as descreva.

Figura 2. Mapa temático do consumo per capita da energia primária em 2012.

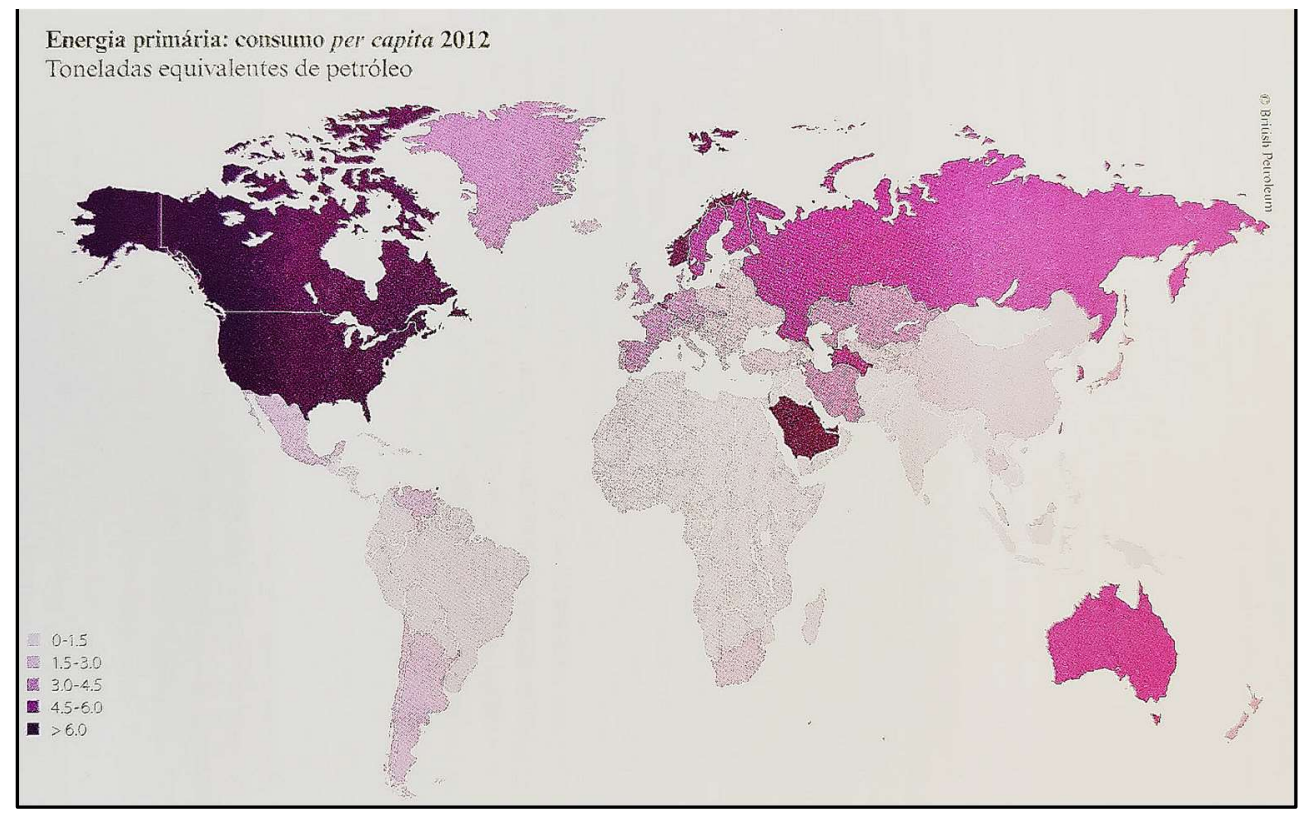

Fonte: SÃO PAULO (2014).

No caso da Espanha, utilizou-se o livro didático Geografia i Història, da Editora Santillana Educación, indicado para o 2 ESO. Este material foi estruturado com base na reforma educacional da Lei Geral de Educação (LGE), em 1970. Na página 24 encontra-se o mapa da Figura 3, referente ao território do Império de Carlos Magno e o mapa do tratado de Verdún. Eles estão acompanhados de quatro questões, sendo que apenas uma mobiliza o pensamento espacial ao questionar quais territórios faziam parte do reino franco; qual foi conquistado por Carlos Magno; e quais faziam parte da península ibérica e em quantos territórios se dividiu o império no ano de 843? As perguntas envolvem mais a identificação e localização dos elementos. 
Figura 3. Mapa do Império de Carlos Magno e do tratado de Verdún.
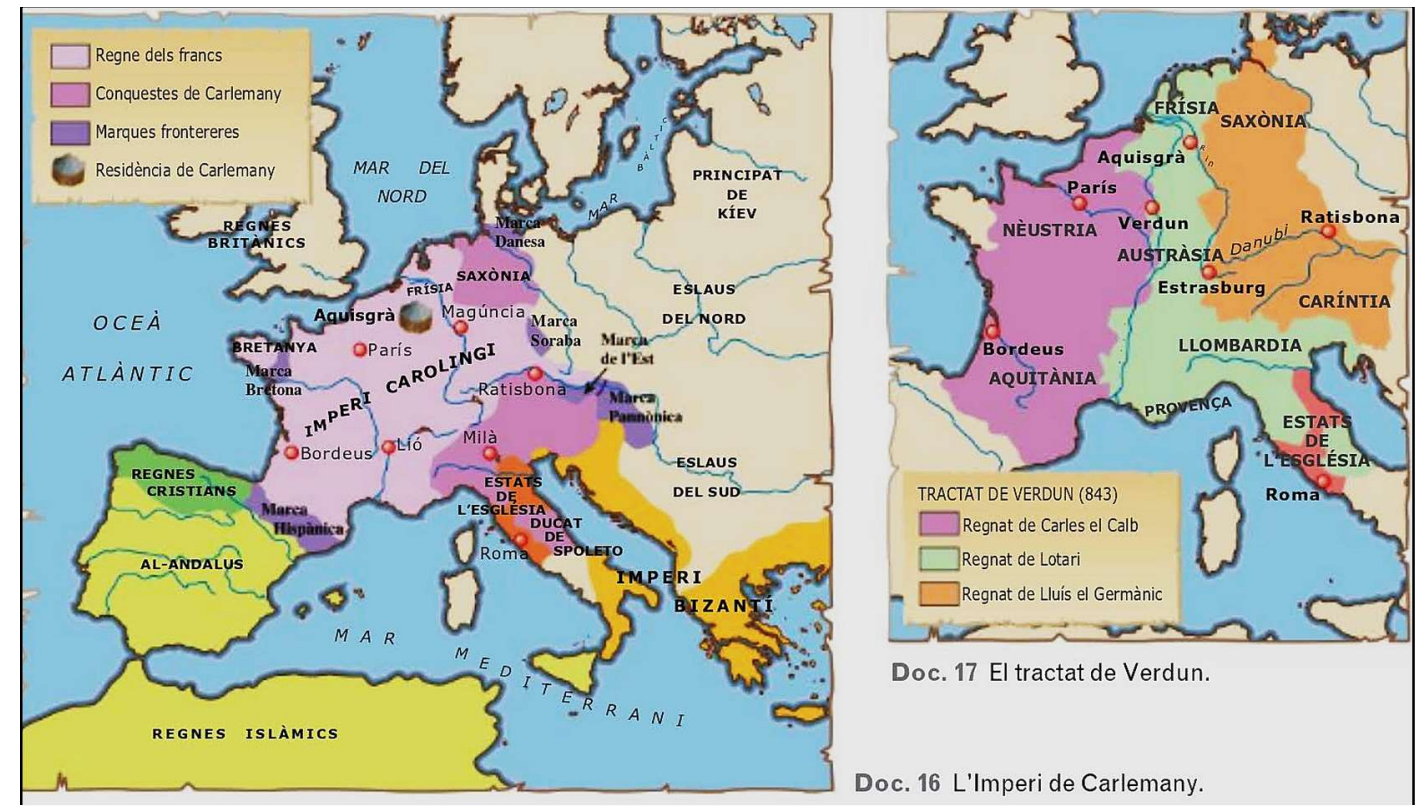

Fonte: Martínez et. al. (2007).

Na página 26, há o mapa com os países que possuem pelo menos $50 \%$ de população islâmica. A partir deste mapa e do disponível na página 22, o estudante deve responder onze questões, das quais nove mobilizam o pensamento espacial, exigindo que utilizem o mapa para localizar áreas e estados e realizem comparações entre os dois mapas, por serem de épocas distintas. Os mapas estão representados nas figuras 4 e 5 a seguir.

Figura 4. Mapa dos países com 50\% ou mais de população islâmica

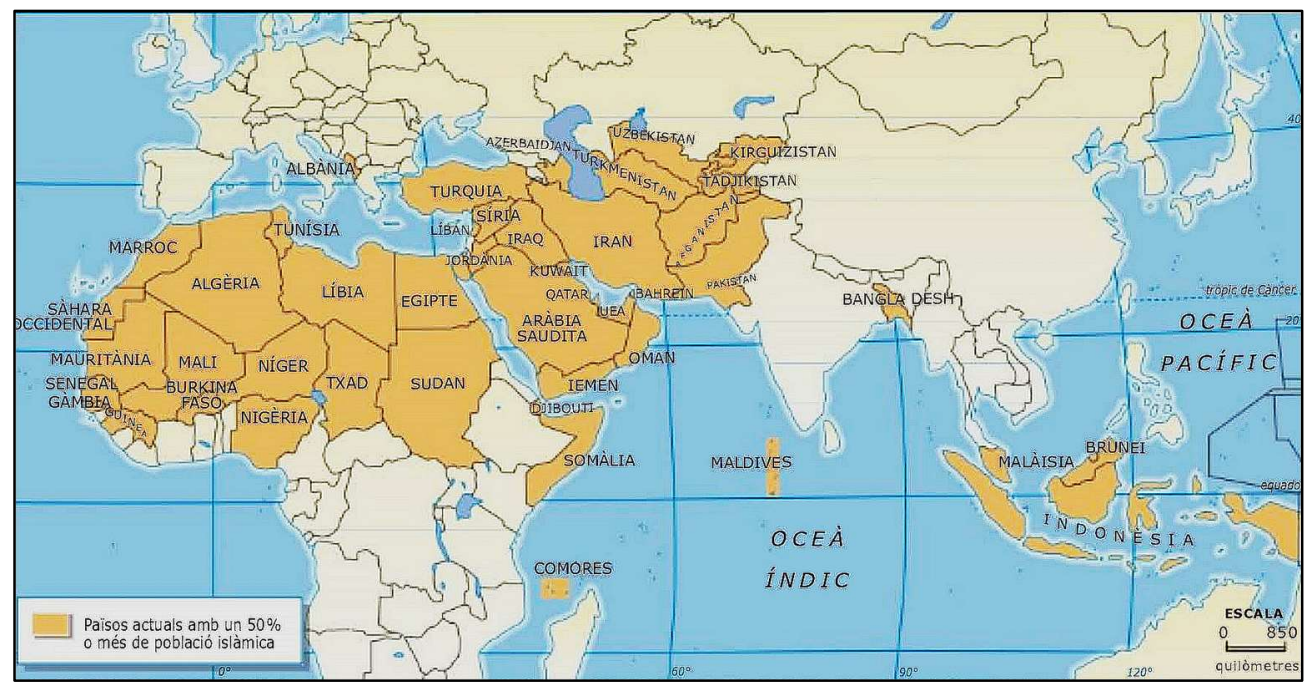

Fonte: Martínez et. al. (2007). 
Figura 5. Mapa da expansão do islã durante a Idade Média.

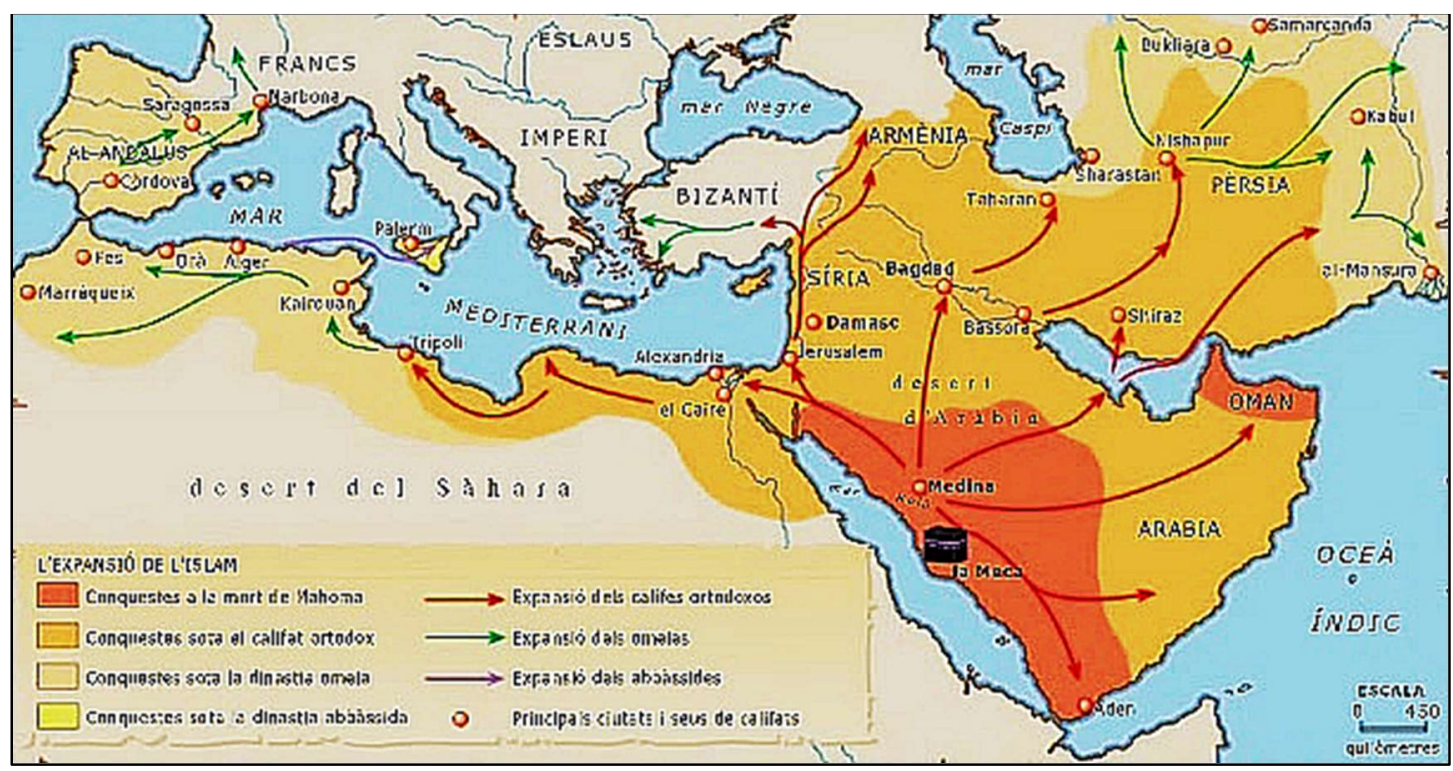

Fonte: Martínez et. al. (2007).

A figura 6 é referente ao mapa localizado na página 89, que solicita que o leitor interprete o mapa respondendo algumas questões relacionadas ao período do avanço do cristianismo. Das sete perguntas, apenas duas mobilizam o pensamento espacial, possibilitando que o estudante reflita sobre os territórios, exigindo um esforço para identificar os territórios conquistados pelos cristãos.

Figura 6. Mapa do avanço dos reinos cristãos

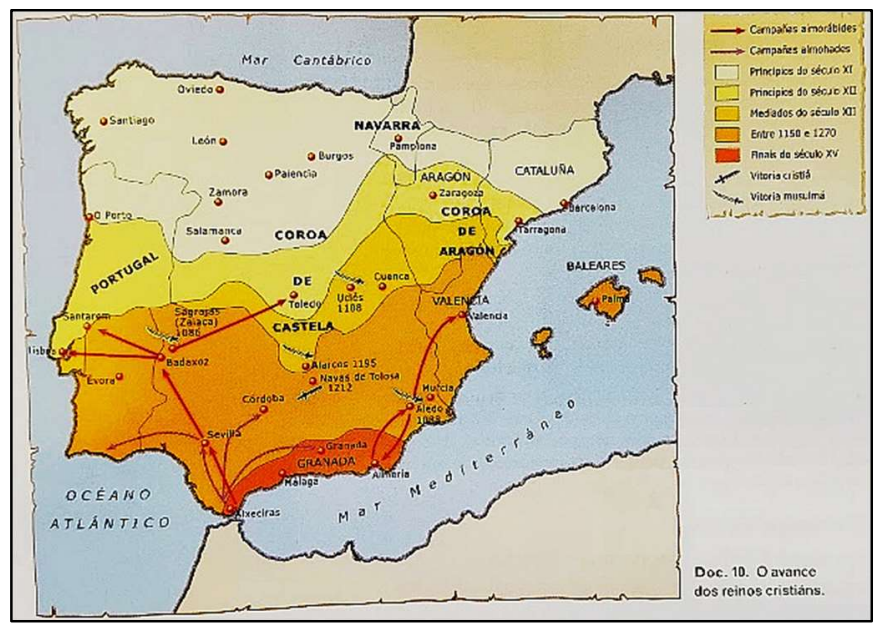

Fonte: Martínez et. al. (2007). 
Já na pág. 229, a figura 7 apresenta o mapa das principais famílias linguísticas do mundo que está acompanhado de questões que pedem que o escolar identifique quais são a família linguística que mais predomina no mapa, para responder quais são os idiomas mais falados. Além disso, quer saber o tamanho desses países. Nenhuma questão envolveu o pensamento espacial.

Figura 7. Mapa das principais famílias linguísticas do mundo

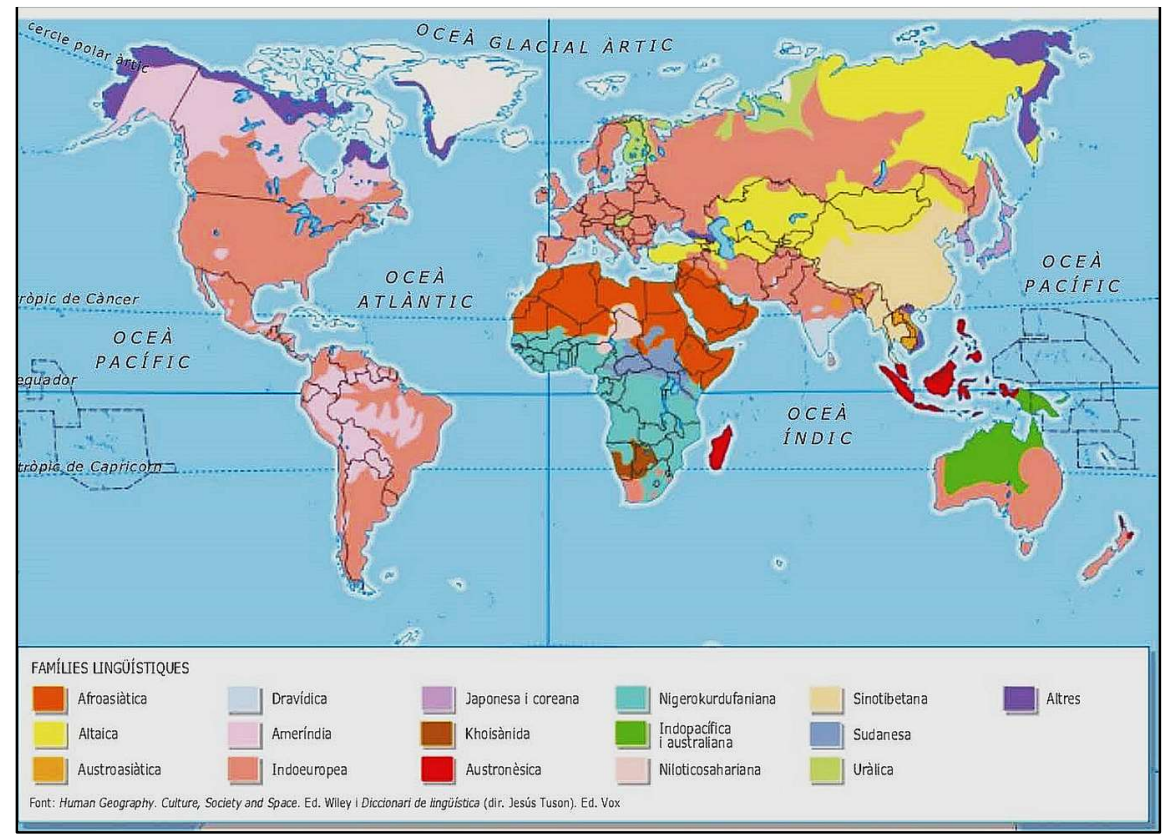

Fonte: Martínez et. al. (2007).

A tabela 2 a seguir apresenta o resultado da análise desses materiais conforme as habilidades de pensamento espacial mobilizadas.

Tabela 2. Análise dos materiais didáticos

\begin{tabular}{|c|c|c|c|c|c|}
\hline Localização & Representação & Conceitos & $\begin{array}{c}\text { Nível de } \\
\text { processamento }\end{array}$ & Habilidades & Aquisições \\
\hline $\begin{array}{l}\text { Caderno do } \\
\text { Professor, } 1^{\mathrm{a}} \\
\text { EM, volume 2, } \\
\text { 2014. Pág. } 85 \text {. }\end{array}$ & $\begin{array}{l}\text { Ordenada; Método } \\
\text { corocromático } \\
\text { ordenado. } \\
\text { Título: } \\
\text { Desflorestamento e } \\
\text { desertificação. } \\
\end{array}$ & Região & $\begin{array}{l}\text { 2)a) input; b) } \\
\text { input; c) } \\
\text { prossesing; d) } \\
\text { input; e) não } \\
\text { espacial; f) input; } \\
\text { g) input; h) input. }\end{array}$ & Nível 2 & Complexas \\
\hline $\begin{array}{c}\text { Caderno do } \\
\text { Professor, } 1^{\mathrm{a}} \\
\text { EM, volume 2, } \\
\text { 2014. Pág. 94. }\end{array}$ & $\begin{array}{l}\text { Quantitativa. Método } \\
\text { coroplético. }\end{array}$ & Região & $\begin{array}{l}\text { Input } \\
\text { input. }\end{array}$ & Nível 2 & Médias \\
\hline
\end{tabular}




\begin{tabular}{|c|c|c|c|c|c|}
\hline & $\begin{array}{c}\text { Título: Energia } \\
\text { primária, consumo } \\
\text { per capita. }\end{array}$ & & & & \\
\hline $\begin{array}{l}\text { Geografia i } \\
\text { Història. } 2 \\
\text { ESO, } 2007 . \\
\text { Pág. } 24 .\end{array}$ & $\begin{array}{l}\text { Qualitativo. Método } \\
\text { corocromático } \\
\text { qualitativo. } \\
\text { Título: O império de } \\
\text { Carlo Magno. } \\
\text { O tratado de Verdún. }\end{array}$ & Território & $\begin{array}{l}\text { 19) não espacial } \\
\text { 20) não espacial } \\
\text { 21) input } \\
\text { 22) não espacial }\end{array}$ & Nível 1 & Simples \\
\hline $\begin{array}{l}\text { Geografia i } \\
\text { Història. } 2 \\
\text { ESO, } 2007 . \\
\text { Pág. } 26 .\end{array}$ & $\begin{array}{l}\text { Qualitativo. Método } \\
\text { corocromático } \\
\text { qualitativo. } \\
\text { Título: Países com } \\
50 \% \text { ou mais de } \\
\text { população islâmica. }\end{array}$ & $\begin{array}{l}\text { Região } \\
\text { Território }\end{array}$ & $\begin{array}{l}\text { 23) a) não espacial } \\
\text { b) input } \\
\text { c) input } \\
\text { d) input } \\
\text { 24) a) input } \\
\text { b) input } \\
\text { c) input } \\
\text { a)input } \\
\text { b)input } \\
\text { extra: não espacial } \\
\text { 25) input }\end{array}$ & Nível 3 & Complexas \\
\hline $\begin{array}{l}\text { Geografia i } \\
\text { Història. } 2 \\
\text { ESO, } 2007 . \\
\text { Pág. } 89 .\end{array}$ & $\begin{array}{l}\text { Qualitativo: usa de } \\
\text { forma equivocada o } \\
\text { método coroplético, } \\
\text { sendo o } \\
\text { corocromático o } \\
\text { correto. } \\
\text { Título: O avanço dos } \\
\text { reinos cristãos. }\end{array}$ & Território & $\begin{array}{l}\text { 6) a) não espacial } \\
\text { b) input } \\
\text { c) input } \\
\text { d) não espacial } \\
\text { 7) não espacial. }\end{array}$ & Nível 1 & Simples \\
\hline $\begin{array}{l}\text { Geografia i } \\
\text { Història. } 2 \\
\text { ESO, } 2007 . \\
\text { Pág. } 229 .\end{array}$ & $\begin{array}{l}\text { Qualitativo. Método } \\
\text { corocromático } \\
\text { qualitativo. } \\
\text { Título: Principais } \\
\text { famílias linguísticas. }\end{array}$ & $\begin{array}{l}\text { Região, } \\
\text { Território, } \\
\text { Espaço }\end{array}$ & $\begin{array}{l}\text { 8) input } \\
\text { 9) não espacial }\end{array}$ & Nível 1 & Simples \\
\hline
\end{tabular}

Fonte: Elaboração própria.

\section{REFERÊNCIAS}

DE MIGUEL, R. Pensamiento espacial y conocimiento geográfico en los nuevos estilos de aprendizaje, Actas del XI Congreso Nacional de Didáctica de la Geografía, 2016, 11-39.

GERSMEHL, P. J.; GERSMEHL, C. A. Spatial thinking by young children: Neurologic evidence for early development and educability, Journal of Geography, 106 (5), 2007, p. 181 19.

JO, I; BEDNARZ, S. W. Evaluating geography textbook questions from a spatial perspective: usng concepts of space, tools of representation, and cognitive processes to evaluate spatiality, Journal of Geography, 108 (1), 2009, 4-13.

NATIONAL RESEARCH COUNCIL. Learning to Think Spatially. The National Academies Press. 2006. Disponível em: https://doi.org/10.17226/11019. Acesso em jan. de 2020. 
SIMIELLI, M. E. R. Cartografia e Ensino: proposta e contraponto de uma obra didática, Memorial para Concurso (Livre Docência), 1996.

TONINI, I.; CLAUDINO, S; SOUTO, X. Mudanças e continuidades nos livros didáticos de Geografia: uma análise comparativa entre Brasil, Espanha e Portugal, Rev. Terra Livre, 2, 2017, 45, 31-61. 